\title{
Preliminary probabilistic prediction of ice/snow accretion on stay cables based on meteorological variables
}

Roldsgaard, Joan Hee; Kiremidjian, A.; Georgakis, Christos T.; Faber, Michael Havbro

Publication date:

2013

Link back to DTU Orbit

Citation (APA):

Roldsgaard, J. H., Kiremidjian, A., Georgakis, C. T., \& Faber, M. H. (2013). Preliminary probabilistic prediction of ice/snow accretion on stay cables based on meteorological variables. Paper presented at 11th international conference on Structural Safety \& Reliability Conference, New York, United States.

\section{General rights}

Copyright and moral rights for the publications made accessible in the public portal are retained by the authors and/or other copyright owners and it is a condition of accessing publications that users recognise and abide by the legal requirements associated with these rights.

- Users may download and print one copy of any publication from the public portal for the purpose of private study or research.

- You may not further distribute the material or use it for any profit-making activity or commercial gain

- You may freely distribute the URL identifying the publication in the public portal 


\title{
Preliminary probabilistic prediction of ice/snow accretion on stay cables based on meteorological variables
}

\author{
J.H. Roldsgaard ${ }^{\mathrm{a}}$, A. Kiremidjian ${ }^{\mathrm{b}}$, C.T. Georgakis ${ }^{\mathrm{a}} \&$ M.H. Faber ${ }^{\mathrm{a}}$ \\ ${ }^{a}$ Department of Civil Engineering, Technical University of Denmark, Building 118, Brovej, 2800 \\ Kgs. Lyngby, Denmark \\ ${ }^{b}$ Department of Civil and Environmental Engineering, Stanford University, School of \\ Engineering, 475 Via Ortega, California, USA
}

\begin{abstract}
The scope of the present paper is to present a framework for assessment of the probability of occurrence of ice/snow accretion on bridge cables. The framework utilizes Bayesian Probabilistic Networks and the methodology is illustrated with an example of the cable-stayed Øresund Bridge. The case study focuses on the ice/snow accretion due to the in-cloud icing or precipitation icing mechanisms and includes probabilistic assessments of the meteorological variables influencing the ice/snow accretion on the stay cables. Different probability distribution functions are utilized for the representation of the meteorological variables and evaluated both by goodness-of-fit test and qualitatively. Conditional probability curves are developed to predict the amount of ice accretion given a set of meteorological conditions using the Gaussian Kernel Smoothing method. The fitted probability distribution functions for the meteorological variables and the conditional ice accretion curves are implemented in a Bayesian Probabilistic Network and the annual average number of ice/snow accretion occurrences is estimated.
\end{abstract}

\section{INTRODUCTION}

The hours of bridge closures and traffic restrictions on bridges has increased along with the number of long span cable supported bridges build since the 1970 's. Some of these unanticipated bridge closures and traffic restrictions are caused by ice or sleet induced vibrations of the cables or ice/snow shedding from the cables. Both can lead to dangerous situations for the bridge users and may be socioeconomically expensive due to closure of the bridges to traffic. The Great Belt Bridge (Denmark) (Kleissl \& Georgakis 2010), the Øresund Bridge (SwedenDenmark), Severn and Second Severn Crossing (England-Wales) (Lai 2009, BBC 2009), Veterans Glass City Skyway Bridge (Toledo, Ohio) (Kumpf et al. 2012), Uddevalla Bridge (Sweden) (Kuhn 2006) and the Port Mann Bridge (Vancouver, Canada) (CBC 2012) all have suffered from ice/snow shedding from the bridge cables. The ice/snow shedding or ice/sleet induced vibrations often come as a surprise to the bridge owners, operators and designers. Appropriate preventive measures could be identified already in the design phase for potentially exposed bridges on the basis of risk assessments.

Design for ice/snow accretion on transmission lines in cold regions is specified and standardized in codes and guidelines such as Eurocode, IEC etc. Probabilistic methods are adopted today in the design of transmission lines by reliability based design methods. However, the transmission line designers focus on the extreme value analysis for ice/snow overload on the conductors to prevent electricity shut down, such as the one experienced in Canada in 1998 (Farzaneh 2000). The bridge engineers, owners and authorities are interested in the occurrence frequency of any ice/snow accretion event that can lead to ice/snow shedding from the cables. Thus the attention in the present paper is directed on the conditions under which ice or snow accretes on the cables and not only on the extreme situations.

Modeling of ice/snow accretion is not a trivial problem. Different types of accretion models have been proposed; mathematically by e.g. Myers and Charpin (2004) and experimentally by e.g. Jones (1998). The former type often requires input parameters that can be difficult to measure such as droplet size whereas the latter type is based on the physics of ice accretion. A probabilistic methodology for estimating the occurrence frequency of ice/snow accretion on bridge cables based on monitoring data is proposed in the present paper. The approach presented can be used in a broader framework for probabilistic assessment of bridge cable fatigue using Bayesian Probabilistic Networks (BPNs), as presented by Roldsgaard et al. (2012). In the present paper the conditions under which ice/snow accretes on cables are described and through probabilistic modeling and parameter estimation appropriate pdf's of the meteorological variables are identified. Based on monitoring data from the vicinity of the Øresund Bridge probabilistic 
models for the relevant meteorological variables and the probability of occurrence of ice/snow accretion on the stay cables is assessed using the proposed framework.

\subsection{Outline of basic conditions for ice/snow accretion}

In order to estimate the occurrence probability of the ice or snow accretion the basic conditions for the ice/snow accretion process is reviewed. Typically ice/snow accretion on cables occurs either by precipitation icing, in-cloud icing or hoar frost. Hoar frost is often neglected in the transmission line design, since the accretion is relatively lightweight. However it is believed that the ice accretion due to hoar frost can induce galloping vibrations of bridge cables and that even small ice lumps can be a hazard for the bridge users, consequently hoar frost should be taken into account in this type of analysis. Precipitation icing can result in glaze, wet snow or dry snow, whereas in-cloud icing can result in soft or hard rime. Precipitation icing occurs at any location where precipitation is present at the same time as freezing temperatures. The type of precipitation icing depends on the vertical temperature layers (Thérialut et al. 2006). The density of the ice that is likely to accrete on the cables can be estimated from values of the temperature and wind velocity through Figure 1. The characteristics of the different icing types can be obtained from Table 1.

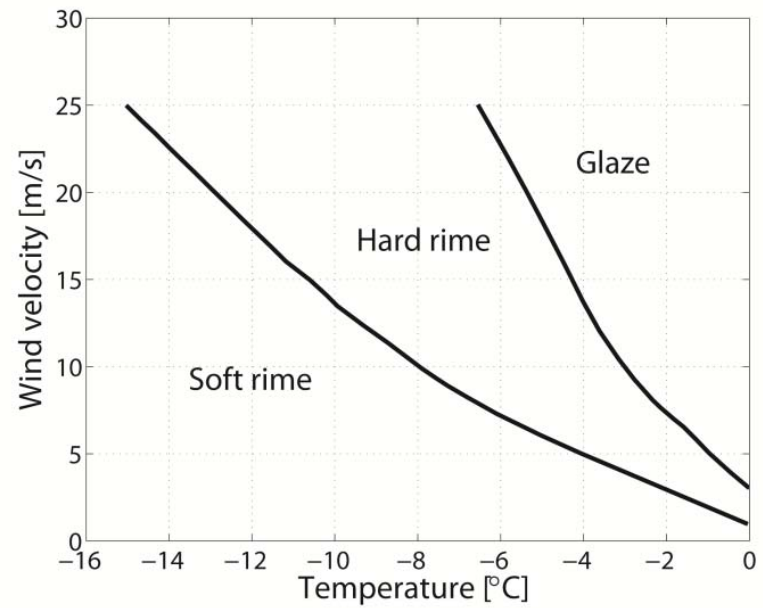

Figure 1. The definition of the different icing types (IEC 60826, 2003).

Table 1. Characteristics of different icing types.

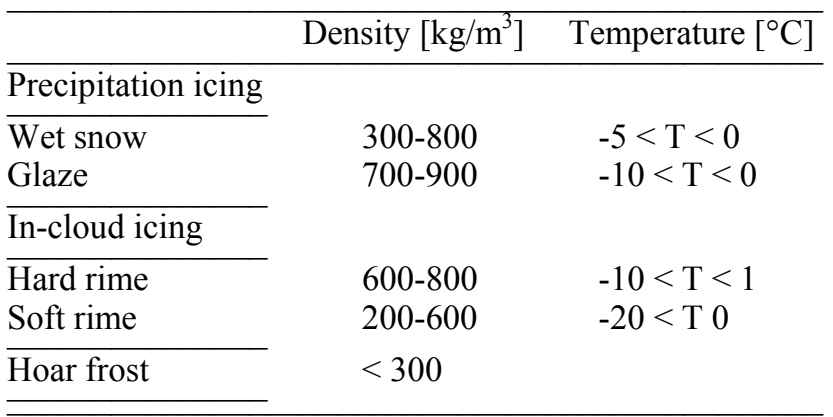

\section{MODEL OVERVIEW}

\subsection{Bayesian Probabilistic Network}

Figure 2 presents the BPN for assessment of the annual probability of occurrence of ice/snow accretion. The BPN represents the causal relationships between the most important variables affecting the two icing mechanisms considered in this analysis; in-cloud icing and precipitation icing. In the model, the states of the variables are represented discretely. Thus in the modeling, it is necessary to discretize all variables with continuous states.

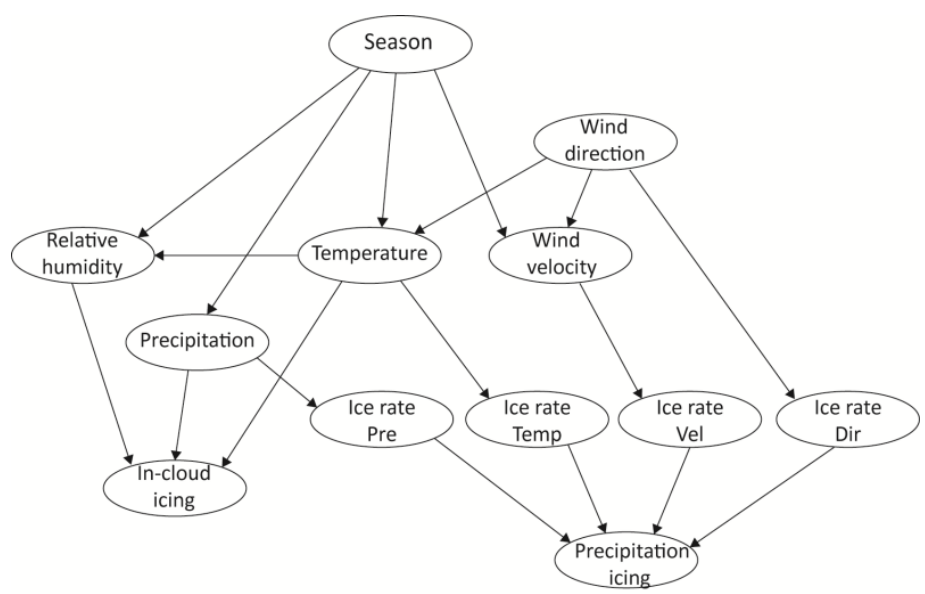

Figure 2. The Bayesian Probabilistic Network: Assessment of annual probability of occurrence of ice/snow accretion on bridge cables.

The assignment of a probability structure to the possible states of each variable in the BPN can be carried out by discretization of the probability distribution, if such a function is defined for the variable considered. Measurements are already discrete and their sampling frequency may be utilized to determine the lower bound and upper bounds in the discretization. Depending on whether the variables in the BPN have only outgoing edges (parent variables) or also ingoing edges (child variables) the discrete states of the variables are assigned unconditional or conditional probability tables, respectively (Faber et al. 2002).

\subsection{Probabilistic Model Constituents}

The meteorological variables are often given as time series (stochastic processes) or in some situations as probability distribution functions (pdfs). The pdfs can directly be discretized and used in the BPN whereas some characteristics about the time series must be identified before a pdf can be used to characterize the variable. Here the investigation of the autocorrelation and cross-correlation functions can be an essential part of the analysis, since it can reveal if the stochastic processes are stationary and correlated with other variables (Madsen 2008). If a stochastic process is stationary and not crosscorrelated with any of the other variables, an appropriate marginal pdf can be identified by model esti- 
mation and testing - using a mixture of physical considerations with data assessment. In the case where the stochastic process is stationary but crosscorrelated to one or more of the variables, however, conditional pdfs must be identified. The dependency structure between two variables should also be apparent from the BPN. In the case the pdfs are not given a priory, different types of probability density functions should be tested in order to find the best estimate. The identified pdfs can be evaluated based on the Quantile-Quantile plot (Q-Q plot), estimated cumulative distribution function (CDF), pdf-plots and of goodness-of-fit tests such as the Kolmogorov-Smirnov test (K-S test). For different variables, the upper or lower tail of their distributions may be of greater importance than the overall distribution. This should be reviewed for each individual variable. To estimate the probability of annual occurrence of ice/snow accretion, a mathematical or experimental accretion models, monitoring data or different criterion can be used.

The described framework for estimating the annual probability of occurrence of ice/snow accretion (icing) on bridge cables is illustrated through a case study of the stay cables of the Øresund Bridge.

\section{ANALYSIS OF THE METEOROLOGICAL DATA FOR THE ØRESUND BRIDGE SITE}

The Øresund Bridge is a cable stayed bridge connecting Denmark and Sweden with a main span of $490 \mathrm{~m}$. Figure 3 shows the location of the Øresund Bridge and Copenhagen Airport. The bridge is oriented in the N-W to S-E direction and the stay cables are arranged in a harp configuration and are inclined with an angle of 30 degrees to the horizon.

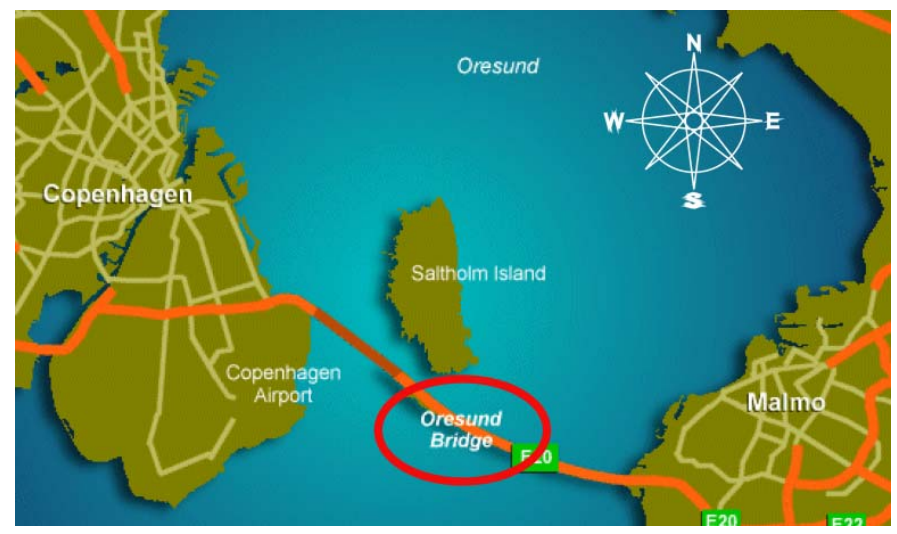

Figure 3. Map of the Øresund link and Kastrup Airport (Denmark) (http://www.worldgreatestsites.com/).

The Danish Meteorological Institute (DMI) has a network of 65 observation stations covering Denmark. In the present paper measurements obtained from station 6180 are treated. This station is located at Copenhagen Airport, which is in flat terrain and close to the ocean. It was chosen to use data from the Copenhagen Airport station, since it is situated only about $10 \mathrm{~km}$ from the Øresund Bridge. This station has 10-min-mean values of the meteorological variables available for every $10 \mathrm{~min}$ since the 25 th of June 2003. The data are obtained from that date until the 31st of December 2011 at 23:50. This gives a total of 447079 data points for the variables: wind velocity, wind direction, relative humidity and temperature. The precipitation is measured every third hour as the accumulated precipitation since the last measurement. Less than $0.5 \%$ of the data points of one of the variables are missing or reported as non-available. If one data point of one of the variables is missing, the equivalent data points of the other variables are also withdrawn.

\subsection{Correlation}

The measurements of the wind velocity, wind direction, temperature, relative humidity and precipitation from Copenhagen Airport are provided as time series (realizations of stochastic processes). The cross correlation between two observed time series $X(t)$ and $Y(t)$ may be analyzed by Equation (1). $X(t)$ and $Y(t)$ can represent any two of the meteorological variables when the cross-correlation between two variables are found.

$$
\rho_{x y}(\tau)=\frac{\frac{1}{n} \sum_{i=1}^{n}\left(x\left(t_{i}\right)-\hat{\mu}_{X}\right)\left(y\left(t_{i+\tau}\right)-\hat{\mu}_{Y}\right)}{\hat{\sigma}_{X} \hat{\sigma}_{Y}}
$$

where $x\left(t_{i}\right)$ is the $i$ th observation of the time series $X(t)$ and $y\left(t_{i+\tau}\right)$ is $(i+\tau)$ th observation of the time series $Y(t) . \tau$ is the time lag between the two observations, $\hat{\mu}_{X}$ and $\hat{\mu}_{Y}$ are the estimated sample means, $\hat{\sigma}_{X}$ and $\hat{\sigma}_{Y}$ is the estimated sample standard deviations of the two observed time series $X(t)$ and $Y(t)$ and $n$ is the number of observations in the time series $(\mathrm{Fa}-$ ber 2012). Since the wind direction is given in degrees and both 0 and 360 degrees indicate north, it does not make physical sense to plot the crosscorrelation function between the wind direction and any other meteorological variable. It is found that the relative humidity and temperature are crosscorrelated, whereas the cross-correlation between the other variables does not reveal any clear trends. It is also found that all the individual stochastic processes can be assumed stationary.

\subsection{Probabilistic modeling of the meteorological variables}

Various distributions types are tested against the different meteorological variables, the outcomes are summarized in the following subsections. The individual fitted distributions are evaluated based on a Quantile-Quantile plot (Q-Q plot), probability density function plot (pdf plot), cumulative distribution function plot (CDF plot) and the D-value of the 
Kolmogorov-Smirnov test (K-S test). Not all of the above mentioned plots are shown in the present paper due to space limitations but were considered in the overall assessment of the different types of probability distributions fitted to the meteorological variables.

\subsection{Wind direction}

The wind direction is defined as a parent node (see Figure 2), which means that it has no incoming edges. Therefore an unconditional probability distribution is fitted to the wind direction data. The wind direction is measured in degrees $10 \mathrm{~m}$ over terrain with 0 and 360 degrees as magnetic north. The wind direction in Denmark is predominantly western (blowing from west) (Cappelen \& Jørgensen 1999) which is also shown in the histogram of the measured data Figure 4 with peaks around 250-270 degrees. The wind direction histogram seen in Figure 4 has a uniform lower part and an upper non-uniform part. To determine which distribution type that best captures the wind direction, a truncated mirrored Log-normal, a truncated Gaussian, and a Beta distribution are tested for the non-uniform part.

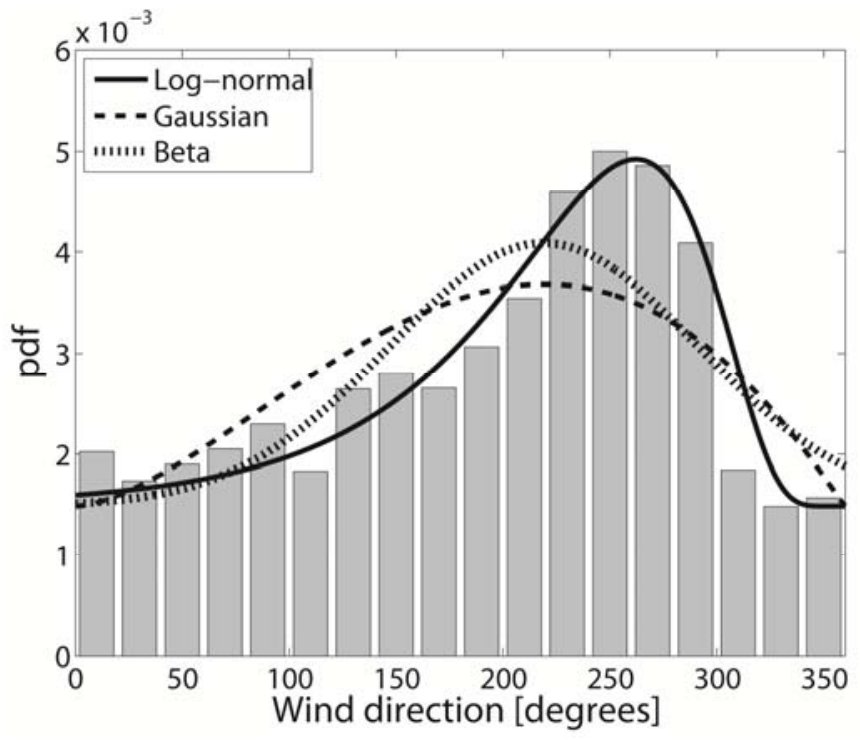

Figure 4. Empirical histogram of the 10-min mean wind direction together with the fitted Log-normal, Gaussian and Beta distributions.

The Q-Q plot, the K-S test and the pdf in Figure 4 all indicate that the truncated mirrored Log-normal and Uniform distribution is the best suited estimate for the wind direction data. The Uniform + truncated mirrored Log-normal distribution is written in a general form in Equation (2).

$$
\begin{aligned}
f(d ; \alpha, \beta) & =c_{1} \cdot f_{D}^{1}(d)+c_{2} \cdot f_{D}^{2}(d) \\
& =c_{1} \cdot f_{D}^{1}(d)+c_{2} \cdot c_{3} \cdot f_{D}^{3}(d) \\
& =c_{1} \cdot \frac{1}{d_{\text {max }}-d_{\text {min }}}+c_{2} \cdot c_{3} \cdot \frac{1}{d \beta \sqrt{2 \pi}} \exp \left(-\left(\frac{(\ln d-\alpha)^{2}}{2 \beta^{2}}\right)\right)
\end{aligned}
$$

where $f_{D}^{d}(d)$ and $f_{D}^{2}(d)$ is the probability distribution of the uniform and non-uniform part respectively, $d$ is the random variable (wind direction), $\beta$ is the standard deviation, $\alpha$ is the mean value, $d_{\max }, d_{\min }$ is the maximum and minimum value the wind direction can obtain, $c_{1}$ is the constant that represent the proportion of the data which is uniform distributed, $c_{2}$ is the constant representing the proportion of the data which is non-uniformly distributed and $c_{3}$ is the constant that re-normalize the Log-normal distribution after truncation.

The truncated mirrored Log-normal + Uniform distribution is discretized into intervals of 5 degrees, which give a total of 12 intervals to fit the probability tables in the BPN in Figure 2.

\subsection{Wind velocity}

The wind velocity in Denmark is known to be correlated with the wind direction, but since the crosscorrelation function could not be established different histograms of the wind velocity given the wind direction are plotted, revealing strong correlation. The wind velocity is also found to exhibit seasonal dependency. For the four seasons the wind direction is divided into 12 intervals of 30 degrees and for each of these intervals the Weibull, truncated Gaussian and Gumbel distribution functions are tested to determine which distribution type best captures the wind velocity. In total 48 different wind velocity data sets are established. The 10-min mean wind velocity is measured $10 \mathrm{~m}$ over terrain at Copenhagen Airport. The histogram of the wind velocity data obtained from the meteorological station at Copenhagen Airport in the winter season for wind directions between [180;210] is shown in Figure 5 together with the fitted Weibull, truncated Gaussian and Gumbel distributions.

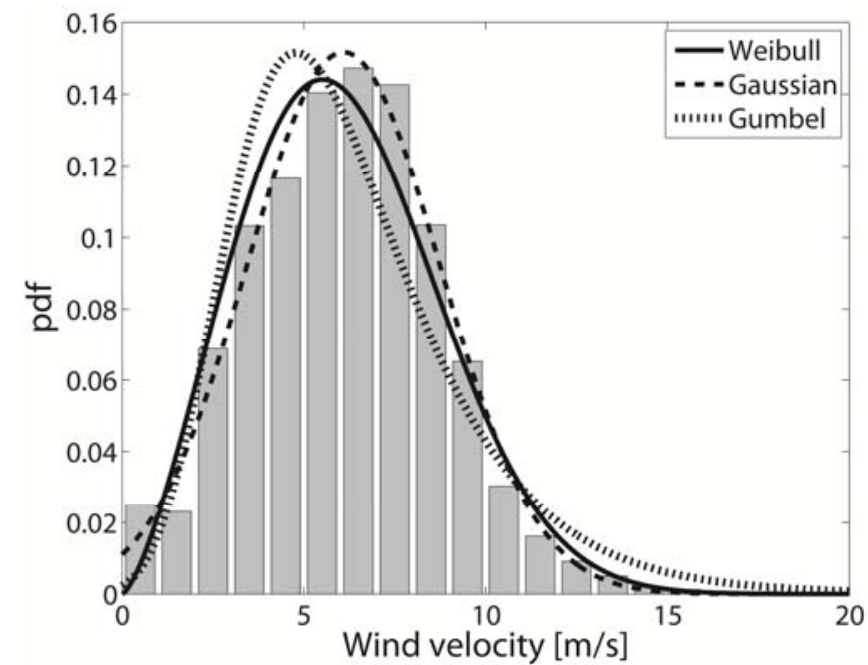

Figure 5. Empirical histogram of the 10-min mean wind velocity together with the fitted Weibull, truncated Gaussian and Gumbel distributions.

Both in-cloud icing and precipitation icing are reported for a wide range of wind velocities. There- 
fore, the overall fit of the wind velocity is of importance. The result of the 48 different probabilistic models and parameter estimations give 37 data sets where the Weibull distribution is chosen as the best estimation and 11 data sets where the Gumbel distribution is chosen as the best estimation. The dominance of the Weibull distribution as the best suited is in accordance with what Carta et al. (2009) and Zhang et al. (2013) report for the mean wind velocity. The Gumbel distribution is more often found describing extreme wind velocities.

\subsection{Precipitation}

The precipitation is seasonally dependent in Denmark, both in terms of type but also amount and duration. In the present analysis only the amount is taken into account and the type and duration left for future analysis. The accumulated precipitation is measured every 3 hours and is measured with a precision of $0.1 \mathrm{~mm}$ at Copenhagen Airport. The precipitation data is divided into four intervals for each season. Precipitation $p<0.1 \mathrm{~mm} / \mathrm{h}, \quad[0.1 ; 0.5]$, [0.5;1.0] and $p>1 \mathrm{~mm} / \mathrm{h}$. The first three intervals are modeled with Uniform distributions and for the fourth interval the Exponential, Gamma and Weibull distribution types are tested.

It is found that zero or below $0.1 \mathrm{~mm} / \mathrm{h}$ of precipitation is the situation for over $88 \%$ of the time during the period between June 2003 and December 2011 , for all seasons. About $1.5-4 \%$ of the time is the precipitation level above $1 \mathrm{~mm} / \mathrm{h}$. The results show that the precipitation above $1 \mathrm{~mm} / \mathrm{h}$ is higher during the summer than the other seasons and lowest in that interval during the winter. In the winter the precipitation for rates between $0.1-0.5 \mathrm{~mm} / \mathrm{h}$ is higher than for the other seasons. The total amount of precipitation is also higher for the summer season than for the other seasons.

Figure 6 shows the histogram of the precipitation data together with the fitted Exponential, Gamma and Weibull distributions. The Exponential distribution is chosen as the best suited for all four seasons. The Exponential $+3 \times$ Uniform distribution are provided in Equation (3).

$$
f(p ; \lambda, \varepsilon)=\left\{\begin{array}{cc}
c_{1} & p<0.1 \\
c_{2} & 0.1 \leq p<0.5 \\
c_{3} & 0.5 \leq p<1 \\
c_{4} \lambda \exp (-\lambda(p-\varepsilon)) & p \geq 1
\end{array}\right.
$$

Where $p$ is the precipitation variable, $c_{l}$ is representing the constant representing the proportion of the data less than $0.1 \mathrm{~mm} / \mathrm{h}, c_{2}$ is representing the distribution for the data values between $0.1-0.5 \mathrm{~mm} / \mathrm{h}, c_{3}$ is representing the proportion between $0.5-1 \mathrm{~mm} / \mathrm{h}$, $c_{4}$ is representing the proportion equal to or above 1 $\mathrm{mm} / \mathrm{h}, \lambda$ is the rate and $\varepsilon$ is the shift greater than zero. The fitted distributions are discretized in order to fit the format of the BPN.

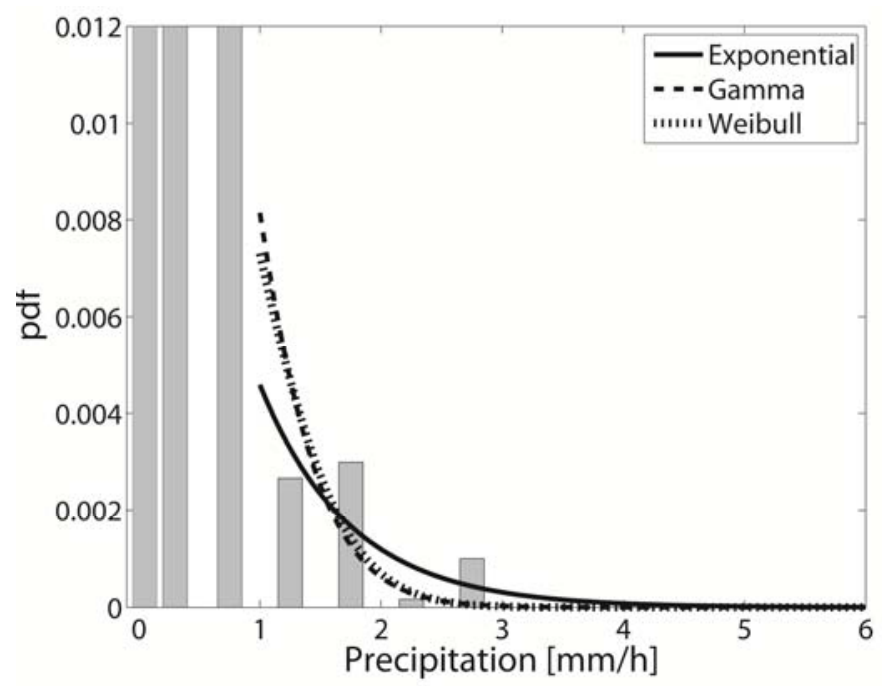

Figure 6. Empirical histogram of the precipitation together with the fitted Exponential, Gamma and Weibull distributions in the winter seasons.

\subsection{Temperature}

The climate and specially the temperature in Denmark are affected by both the ocean and the continent. The temperature is therefore dependent on both the season and the wind direction (Cappelen \& Jørgensen 1999). The temperature is measured in degrees Celsius $2 \mathrm{~m}$ over terrain at Copenhagen Airport. Different probability distributions are fitted to the temperature data conditional on the season and the wind direction. As for the wind velocity four seasons are used and the wind direction is divided into 12 intervals of 30 degrees each. This gives in total 48 different data sets of the temperature. The Gaussian, Log-normal, Weibull and Gamma distributions are modeled and their parameters estimated for each of the 48 data sets. The assessment of the fitting does prioritize the lower tail at which temperatures ice/snow accretion occur. For 19 of the data sets the Gaussian distribution is the best model at the lower tail, for two data sets the Log-normal is the best, for 12 data sets the Weibull is the best and for 15 data sets the Gamma is the best. In the spring the Gamma is the most common, in the summer seasons the Gaussian is the most often chosen, in the fall no clear trend appears and in the winter seasons the Weibull is generally the best suited model. The best model for each of the 48 data sets is discretized and implemented in conditional probability tables in the BPN.

Figure 7 shows an example of an empirical histogram of the temperature data for the winter seasons 
given the wind direction is in the interval between [30;60] degrees. The probabilistically modeled Weibull, Gaussian, Log-normal and Gamma distributions are also shown in Figure 7. It is difficult to

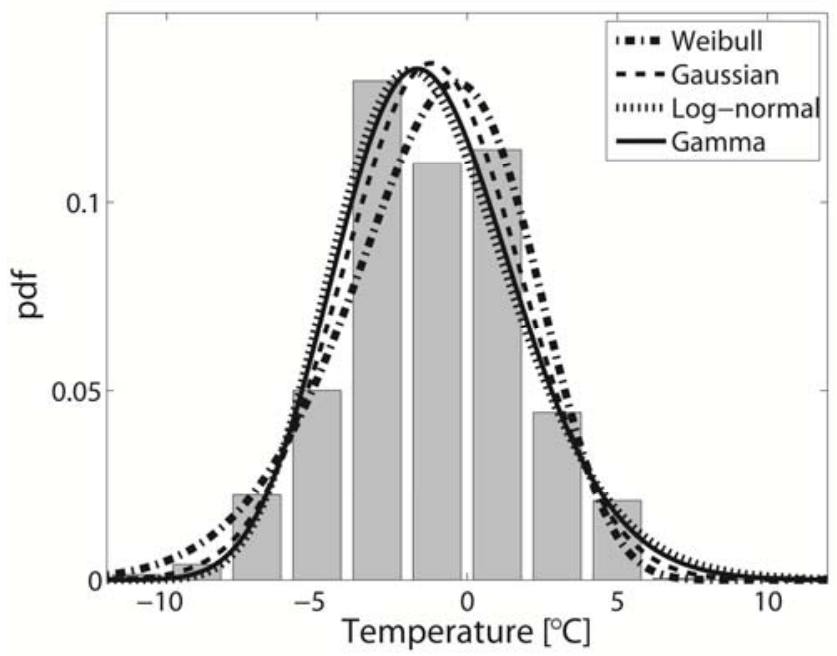

Figure 7. Empirical histogram of the 10-min mean value of the temperature in the winter seasons for wind direction [30;60[ degrees together with the fitted Weibull, Gaussian, Log-normal and Gamma distributions.

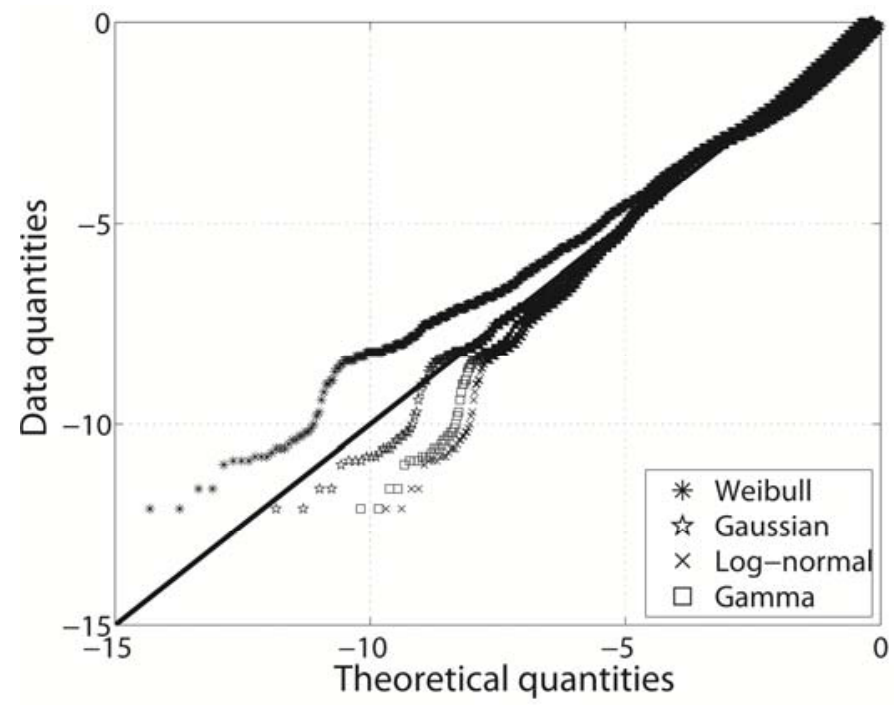

Figure 8. Q-Q plot of the 10-min mean value of the temperature in the winter seasons for wind direction [30;60] degrees together with the quantities of the fitted Weibull, Gaussian, Log-normal and Gamma distributions.

evaluate the fit at the lower tail only from Figure 7, but by the Q-Q plot in Figure 8 it is clear that the Gaussian distribution approximated the lower temperatures better than the other distribution types, though the estimate still deviates from the data.

\subsection{Relative humidity}

From the correlation analysis it is found that the relative humidity and temperature are strongly correlated. The relative humidity is also found dependent on the season, therefore probability density functions conditional on the season and temperature are identi- fied to model the relative humidity data. The 10-min mean value of the relative humidity of the air is measured at Copenhagen Airport in percentage [\%]. The relative humidity data is divided into the four seasons and for each season the data is furthermore

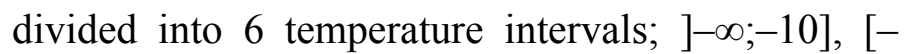
$10 ;-5],[-5 ; 0],[0,10],[0,20],[20 ; \infty[$. This gives a total of 24 data sets. For some of the seasons not all temperature intervals are represented. In total 19 data sets of the relative humidity are created. The truncated mirrored Log-normal, truncated mirrored Weibull, truncated mirrored Gamma and Beta distribution are all modeled and tested for the relative humidity data sets. The relative humidity is important for the in-cloud icing mechanism, which requires that the relative humidity is $95 \%$ or above. Therefore extra attention on the upper tail is paid to the different estimated probability distribution functions. The Weibull distribution is the best model for 7 of the data sets, the Gaussian and Log-normal for one data set each, the Gamma for 3 of the data sets and the Beta for 6 of the data sets. The last data set is best modeled by a Uniform distribution.

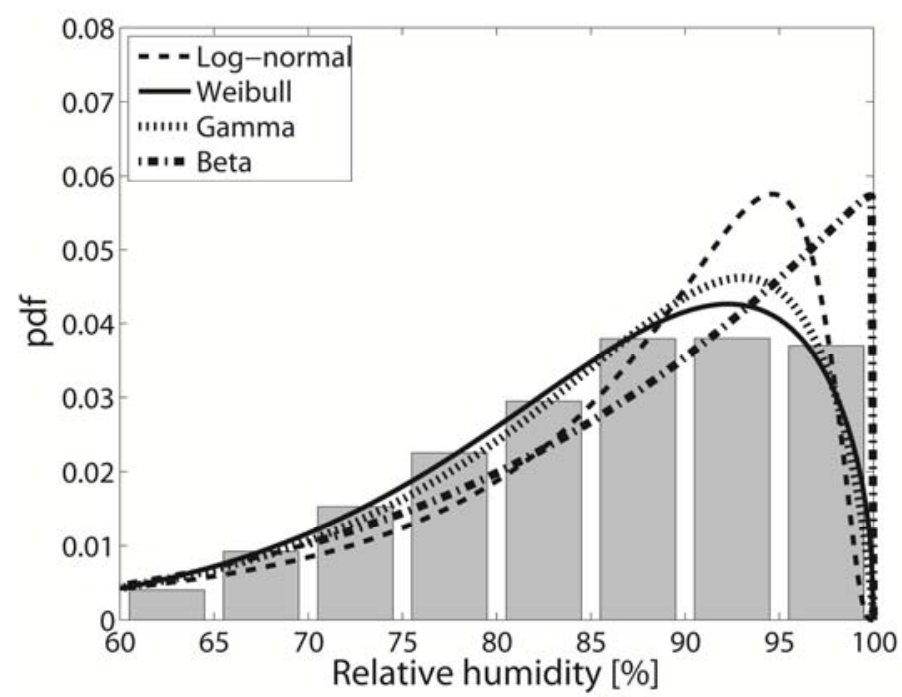

Figure 9. Empirical histogram of the 10-min mean value of the relative humidity in the winter seasons for temperatures in the interval $[-5 ; 0$ [ degree Celsius together with the fitted Lognormal, Weibull, Gamma and Beta distributions.

Figure 9 shows the empirical histogram of the relative humidity data together with the different tested probability distributions for the winter seasons for temperatures between $-5-0^{\circ} \mathrm{C}$. The Weibull distribution is chosen as the best model for the data shown in Figure 9. The expressions for the truncated mirrored Log-normal, truncated mirrored Weibull, truncated mirrored Gamma and Beta distributions is given by Equation (4)-(7) respectively.

$$
f(r h ; \alpha, \beta)=c_{1} \frac{1}{(-r h+100) \beta \sqrt{2 \pi}} \exp \left(-\left(\frac{(\ln (-r h+100)-\alpha)^{2}}{2 \beta^{2}}\right)\right)
$$


where $r h$ is the relative humidity variable, $\alpha$ is the mean value of the Log-normal, $\beta$ is the standard deviation and $c_{1}$ is the normalization constant after truncation of the distribution.

$f(r h ; k, c)=c_{1} \frac{k}{c}\left(\frac{-r h+100}{c}\right)^{k-1} \exp \left(-\left(\frac{-r h+100}{c}\right)^{k}\right)$

where $k$ is the shape parameter and $c$ is the scale parameter.

$f(r h ; k, \theta)=c_{1} \frac{1}{\theta^{k}} \frac{1}{\Gamma(k)}(-r h+100)^{k-1} \exp \left(-\frac{(-r h+100)}{\theta}\right)$

where $k$ is the shape parameter and $\theta$ is the scale parameter.

$$
f(r h ; a, b, r, t)=c_{1} \frac{\Gamma(r+t)}{\Gamma(r) \Gamma(t)} \frac{(r h-a)^{r-1}(b-r h)^{t-1}}{(b-a)^{r+t-1}}
$$

where $a$ is the lower bound of $r h, b$ is the upper bound of $r h, r$ is the shape parameter and $t$ is also a shape parameter. The modeled conditional probability distribution functions are discretized to fit the probability table format of the BPN.

\section{ICE ACCUMULATION RATES}

The probability density function of the ice rate conditional on the meteorological variables can be used not only to assess the probability of icing but also to assess the probability distribution of the amount of ice/snow accreted on the cables. The latter analysis is outside the scope of the present paper. The development of the probability density functions of the ice rate given the wind direction, wind velocity, temperature and precipitation is described herein.

The reported data of real-time measurements of precipitation icing on an instrumented $315-\mathrm{kV}$ line at Mont Bélair, Quebec, Cananda is reported as scatter plots by Farzaneh \& Savadjiev (2005). Two of the scatter plots are reconstructed in Figure 10 and 11 (y-axis to the left), which shows the ice accumulation rate in $\mathrm{kg} / \mathrm{m} / \mathrm{h}$ as function of the meteorological variables: wind direction and temperature. The original plots by Farzaneh \& Savadjiev (2005) depict both the ice accumulation rate and the ice shedding with a Gaussian Kernel smoothing line. The ice shedding is left out of the analysis in the present paper and the Gaussian Kernel Smoothing Method is used to find the conditional probability for the ice accumulation rates to avoid binning of the data. Binning of the ice rate data would result in the conditional probability being strongly influenced by the bin size. The conditional probability of the ice rate equal to or exceeding a specific level of the ice rate given a value of the wind direction is provided by Equation (8) (Noh et al. 2011).

$$
\hat{G}_{i}\left(w_{d i r_{j}}\right)=\frac{\sum_{m} I\left(i r_{m} \geq I R_{i}\right) K_{j}\left(w d i r_{m}\right)}{\sum_{n} K_{j}\left(w d i r_{n}\right)}
$$

where $\hat{G}_{i}\left(w d i r_{j}\right)$ is the conditional probability of the ice rate given the $j$ th wind direction $\left(w d i r_{j}\right), I\left(i r_{m} \geq\right.$ $\left.I R_{i}\right)$ is an indicator function which is 1 if $i r_{m} \geq I R_{i}$ and 0 if $i r_{m}<I R_{i}, K_{j}\left(w d i r_{m}\right)$ or $K_{j}\left(w d i r_{n}\right)$ is the kernel for the $m$ th and $n$th value of the wind direction and $i r_{m}$ is the $m$ th value of the ice accretion given in $\mathrm{kg} / \mathrm{m} / \mathrm{h}$. A symmetric kernel is chosen so the weight is assigned equally around the $m$ th or $n$th value of the ice rate considered. For the present analysis the Gaussian Kernel is used for all the meteorological variables. The bandwidth/standard deviation of the kernel can be estimated by Equation (9) (Silverman 1986).

$$
h=1.06 \hat{\sigma} n^{-1 / 5}
$$

where $\hat{\sigma}$ is the sample standard deviation of the wind direction data samples and $n$ is number of wind direction data points. The four different ice rate states are defined as; $I R_{1}=0.025$ (small), $I R_{2}=0.05$ (intermediate), $I R_{3}=0.1$ (moderate) and $I R_{4}=0.15$ (large).

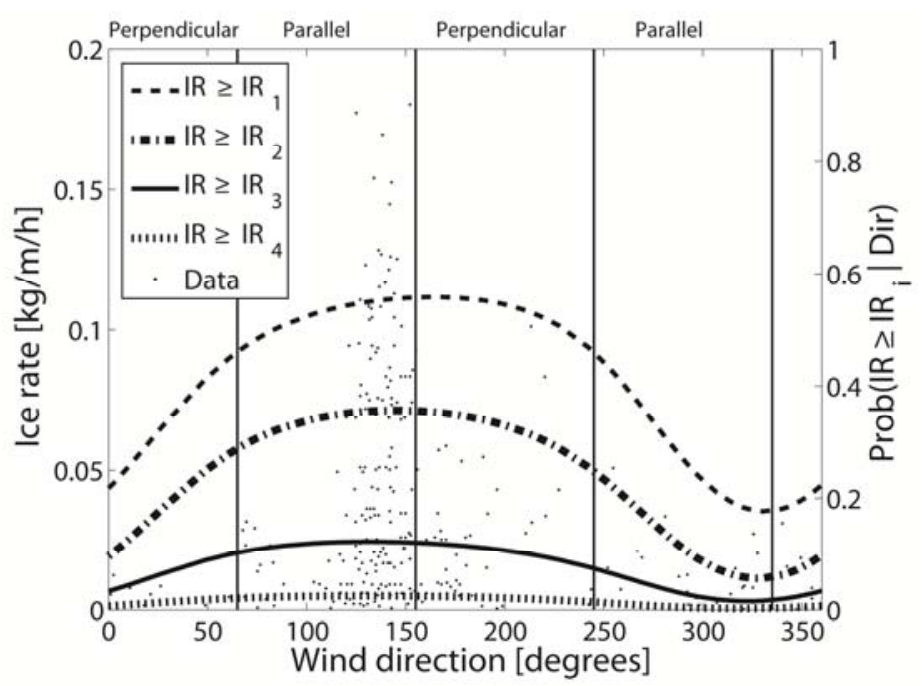

Figure 10. Scatter plot of the ice rate given the wind direction together with conditional probability of the ice rate levels.

Figure 10 and 11 show the results of the Gaussian Kernel Smoothing for the wind direction and temperature respectively. The results for the wind velocity and precipitation are not included due to space limitations.

The Gaussian Kernel Smoothing for the wind direction is a special case, since the wind direction is a polar plot, which means that 0 degrees equals 360 degrees. Consequently the ice rate values for the wind directions close to 0 and 360 degrees are duplicated so that the data points at 100 degrees have the same weights on the probability at 360 degrees as the data points at 260 degrees. The wind directions are given with 0 and 360 degrees as magnetic north, 


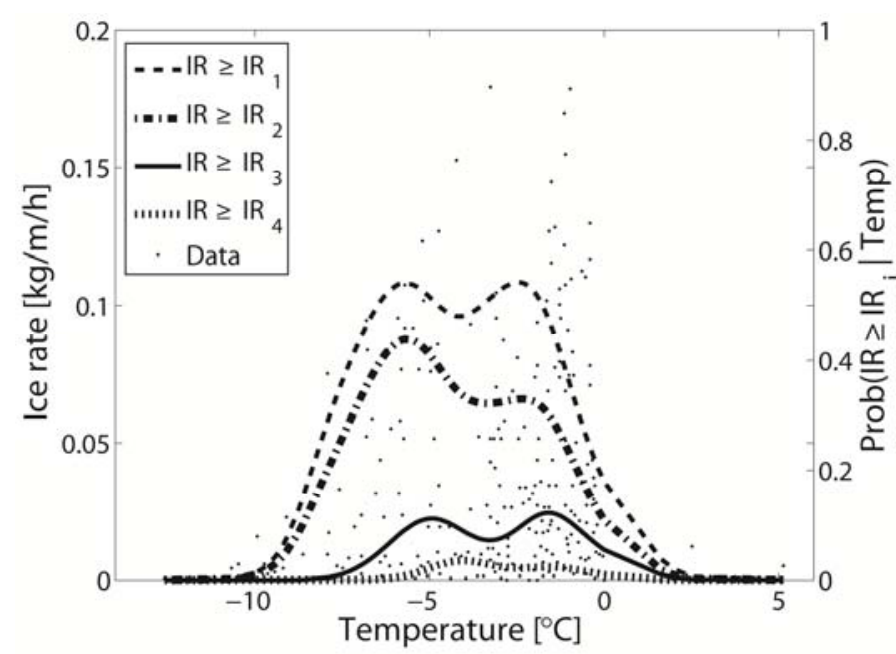

Figure 11. Scatter plot of the ice rate given the temperature together with conditional probability of the ice rate levels.

but regarding ice accretion on cables it is more interesting whether the wind is parallel or perpendicular to the cable. The parallel and perpendicular sections are marked in Figure 10; these sections are shifted to fit the direction of the stay cables of the Øresund Bridge. The sections are defined as \pm 45 degrees from the parallel and perpendicular axis of the Øresund Bridge cables.

Figure 11 shows the scatter plot of the ice rate given the temperature together with the conditional probability of an ice rate value. Few data sets have been observed for temperatures below $-10^{\circ} \mathrm{C}$ and only two data points for temperatures above $0^{\circ} \mathrm{C}$. There are a cluster of data points just below zero degrees, which means the Gaussian Kernel Smoothing method would overestimate the probability of ice accumulation for temperatures above zero degrees. To reduce the error of overestimating the ice rate at positive temperatures artificial points with zero ice rate at $+2{ }^{\circ} \mathrm{C}$ are simulated to force the probability down to zero for positive temperatures.

From the conditional probability of the ice rates the cumulative distribution functions (CDFs) given the meteorological variables are found. Linear interpolation between the ice rate states is used to create the CDFs. More ice rate states could easily be established, which would make the CDFs smoother. The CDFs are differentiated through numerical methods to obtain the probability density function of the ice rates given the meteorological variables.

\subsection{Probability of ice/snow accretion}

The probability of icing due to either in-cloud icing or precipitation icing is estimated through the BPN in Figure 2. For the in-cloud icing mechanism it was assumed that icing would occur for temperature between $-11^{\circ} \mathrm{C}$ and $2^{\circ} \mathrm{C}$, precipitation below $0.1 \mathrm{~mm} / \mathrm{h}$ and relative humidity equal to or above $95 \%$. For the precipitation icing the developed probability functions conditional on the wind direction, wind velocity, temperature and precipitation are used.
The result for the in-cloud icing is that about 2.19 days per year the meteorological conditions for incloud icing occur. The 2.19 days per year are not consecutive but in 10-min intervals, since all the input data is given as 10-min mean values. The meteorological conditions for precipitation icing occur about 1.83 days per year, this number is also not consecutive but in 10-min intervals. A total of 4 days per year in 10 minutes intervals, where the conditions for an icing event are present, is in line with the known number of closures of the Great Belt Bridge also located in Denmark about $100 \mathrm{~km}$ west of the Øresund Bridge.

\section{SUMMARY AND CONCLUSIONS}

A framework for the probabilistic modeling and analysis of occurrence of ice/snow accretion is proposed and a modeling scheme set up and illustrated with a case study of the Øresund Bridge. The relevant meteorological parameters are identified and various probability distributions are fitted and tested to the meteorological variables. Probability density functions of the ice rates given the meteorological parameters are developed through the Gaussian Kernel Smoothing technique, CDFs and differentiation. The Bayesian Probabilistic Network presented in Figure 2 is used to estimate the yearly occurrence of ideal meteorological conditions for in-cloud and precipitation icing. The result of the BPN evaluation showed that the conditions occur in total about 4 days per year.

The current model in its present state lacks the capability to estimate the duration of each icing event or duration of the meteorological conditions favorable for ice/snow accretion.

\section{REFERENCES}

BBC, (2009). http://news.bbc.co.uk/2/hi/uk_news/wales/south east $/ 8426267 . s t m$

Cappelen, J. \& Jørgensen, B. 1999. Observed Wind Speed and Direction in Denmark - with Climatological Standard Normals, 1961-90. DANISH METEOROLOGICAL INSTITUTE, Technical report 99-13.

Carta, J.A., Ramirez, P. \& Velazquez, S. (2009). A review of wind speed probability distributions used in wind energy analysis: Case studies in the Canary Islands. Renewable and Sustainable Energy Reviews, Vol. 13, p. 933-955.

CBC, (2012). http://www.cbc.ca/news/canada/british-columbia /story/2012/12/20/bc-port-mann-ice.html

Faber, M. H. 2012. Statistics and Probability Theory: In Pursuit of Engineering Decision Support. Springer Verlag.

Faber, M.H. \& Kroon, I.B. \& Kragh, E. \& Bayly, D. \& Decosemaeker, P. 2002. Risk assessment of decommissioning options using Bayesian networks. Journal of Offshore Mechanics and Arctic Engineering, 124: 231-238. 
Farzaneh, M. (2008). Atmospheric icing of power networks. Springer, chapter 2 .

Farzaneh, M. \& Savadjiev, K. (2005). Statistical analysis of field data for precipitation icing accretion on overhead power lines. Power Delivery, IEEE Transactions on, Vol. 20, No. 2, 1080-1087.

Farzaneh, M. (2000). Ice accretions on high-voltage conductors and insulators and related phenomena. Philosophical Transactions: Mathematical, Physical and Engineering Sciences, Vol. 358, No. 1776 2971-3005.

IEC 60826, (2003). Design criteria of overhead transmission lines A, COMESA.

Jones, K. F. (1998). A simple model for freezing rain ice loads. Atmospheric Research, Vol. 46, Issues 1-2, p. 87-97.

Kleissl, K. \& Georgakis, C. T. (2010). Bridge ice accretion and de- and anti-icing systems: A review. The 7th International Cable Supported Bridge Operators' Conference, China.

Kuhn, E. (2006). Maintenance with Industrial Rope Access: Uddevalla Bridge - A Case Study. IABSE Symposium Report, IABSE Conference: Operation, Maintenance and Rehabilitation of Large Infrastructure Projects, Bridges and Tunnels, Copenhagen 2006

Kumpf, J., Helmicki, A., Nims D.K., Hunt, V. \& Agrawal, S. (2012). Automated Ice Inference and Monitoring on the Veterans' Glass City Skyway Bridge. Journal of Bridge Engineering, ASCE, Vol. 17, p. 975-978.

Lai, T. (2009). Critical Analysis of the Shoots Bridge, central span of the Second Severn Crossing. Proceedings of Bridge Engineering 2 Conference 2009, April 2009, University of Bath, Bath, UK

Madsen, H. (2008). Time series analysis. Chapman \& Hall/CRC, Taylor \& Francis Group.

Myers, T.G. \& Charpin, J.P.F. (2004). A mathematical model for atmospheric ice accretion and water flow on a cold surface. International Journal of Heat and Mass Transfer, Vol. 47, p. 5483-5500.

Noh, H.Y., \& Lignos, D.G., \& Nair, K.K., \& Kiremidjian, A.S. (2011) Development of fragility functions as a damage classification/prediction method for steel moment-resisting frames using a wavelet-based damage sensitive feature. Earthquake Engineering \& Structural Dynamics, Vol. 41, p. 681-696.

Roldsgaard, J. H., Georgakis, C. T. \& Faber, M. H. (2011).

Estimation of the failure probability of a single strand subjected to combined axial and bending stress. Proc. Int. Symp. On Reliability Engineering and Risk Management, IASSAR, Yokohama, Japan.

Silverman, B.W. (1986). Density estimation for statistics and data analysis, Chapter 3. Chapman \& Hall, CRC.

Theriault, J.M., Stewart, R.E., Milbrandt, J.A. \& Yau, M.K. (2006). On the simulation of winter precipitation types. Journal of Geophysical Research: Atmospheres, Vol. 111.

Zhang, J., Chowdhury, S., Messac, A. \& Castillo, L. (2013). A multivariate and multimodal wind distribution model. Renewable Energy, Vol. 51, p. 436-447. 